\title{
A Comparative Study of German Modern Apprenticeship System and Chinese Order-Class Mode-Based on the Perspective of Institutional Complementarity
}

\author{
Wenchao Jiang \\ Zhejiang Financial College
}

\begin{abstract}
In Western countries, the modern apprenticeship system has evolved into a variety of cultivation forms in the process of educational practice, showing a characteristic of institutional diversity that can be explained by the theory of institutional complementarity. Firstly, this paper constitutes an analytical framework of institutional complementarity based on three elements, namely, "regulative", "normative" and "cultural-cognitive" elements. Under this framework, this paper conducts a comparative analysis of the differences and rules of the institutional complementarity between German modern apprenticeship system and Chinese order-class mode. The results show that: (1) two major forms of institutional complementarity are mutual reinforcement and mutual compensation, and a developmental system tends to take the form of mutual reinforcement while a balanced system tends to adopt mutual compensation; (2) a virtuous circle of institutional complementarity is inseparable from quality assurance; (3) the core of institutional complementarity lies in providing good career prospects; (4) the complementarity also exists in systems of quantity function and that of quality function. Finally, this paper proposes policy recommendations on how to establish a modern apprenticeship in developing countries based on the analysis of policy complementarity.
\end{abstract}

\section{Keywords}

Modern Apprenticeship • Order-class • Institutional Complementarity • Vocational Education

\footnotetext{
${ }^{1}$ Correspondence to: Wenchao Jiang (MA), Zhejiang Financial College, Hangzhou 310018, China. Email: jiangwenchaofox@163.com
}

Citation: Jiang W. C. (2018). A Comparative Study of German Modern Apprenticeship System and Chinese Order-Class Mode--Based on the Perspective of Institutional Complementarity. Educational Sciences: Theory \& Practice, 18 (5), 1005 1015. http://dx.doi.org/10.12738/estp.2018.5.004 
In the book Made in China 2025, a beautiful blueprint is depicted about the development of manufacturing industry in the post-industrial era in China. The realization of this blueprint requires a great number of technical workers equipped with "Industry 4.0" ability. As China's modern industry is developing and upgrading, there is a greater demand for technical workers. However, as a major source for applied talents, most Chinese higher vocational colleges still adopt a traditional talent training method, that is, they work behind closed doors in isolation. The problem of the mismatch between the supply end and the demand end needs to be solved. The modern apprenticeship system is an important measure to promote the interaction between the education system and the industrial economic system, expand the channel for the growth of technical talents and push forward the construction of a modern vocational education system. With its effective personnel training results in Western countries, it has proven to be in accordance with the rules of vocational education. In this context, the modern apprenticeship system in Germany, Britain and other countries has gradually attracted the attention from domestic education field and the government. In 2014, the State Council of China promulgated the Decision on Accelerating the Development of Modern Vocational Education, proposing to "carry out the pilot of modern apprenticeship system of joint enrollment and joint training between schools and enterprises and promote the educational mode of school-enterprise integration".

Nowadays, both the Chinese higher vocational colleges and the government have recognized that developing modern apprenticeship system is an effective way to transform the talent training model and improve the quality of education, but many practical problems still exist in the implementation. For example: (1) Is there any essential difference between the school-enterprise cooperation order-class and the modern apprenticeship system? (2) Strictly speaking, the implementation environment of modern apprenticeship in China is imperfect as the degree of liberalization of the Chinese labor market is very high, enterprises only believe in meritocracy and the employment of technical workers is in high mobility. Under such circumstances, how to build a Chinese version of modern apprenticeship in the existing institutional environment?

With an aim to provide solutions for the above questions and taking the analytical framework of institutional complementarity as a basis, this paper intends to deeply dissect the institutional structure of the German modern apprenticeship system and the Chinese order-class mode, open the black box of the institutional complementarity of modern apprenticeship system as well as illustrate the school-enterprise order-class training mode so as to explore the differences and rules of these two kinds of vocational education institutions. Besides, based on the existing policy environment, this paper proposes policy recommendations to promote the development of the Chinese apprenticeship system.

\section{The Establishment of An Analytical Framework for Institutional Complementarity}

Modern apprenticeship is the result of mutual compromise between social forces and the product of mutual construction of social elements (Hall, 2001). In countries like Germany and Britain, the modern apprenticeship system is not a unitary or isolated policy but a collection of relevant supporting systems in various fields like economy, education, society and so on. Other systems are compatible with the modern apprenticeship system in structure so there is a complementary relationship between them. Such kind of institutional complementarity 
is an implicit force that binds and influences different institutional forms. As a result, it will be biased to analyze a certain system without taking into consideration other policy institutions in relevant fields. Therefore, this paper takes a collection of relevant systems as the research object.

The first step of the analysis is to dissect the institutional structure of the modern apprenticeship system. With regards to the classification of institutions, the famous American sociologist W. Richard Scott proposed the three-element theory concerning regulative, normative and culture-cognitive elements. Among them, regulative elements emphasize external and explicit regulations like rule setting, rewards and punishments, as well as supervision; normative elements are based on rules concerning moral evaluation and social responsibility; cultural-cognitive elements are consistent beliefs and behavioral logic among group members. Most of the institutional combinations are not the result of the acting of one single element, but comes as the product of the linear relationship between the three fundamental elements. Based on these three elements, Scott established an analytical framework for institutions, as shown in Table 1.

Table 1

Mechanism of Three Major Elements of Institutional Analysis

\begin{tabular}{|c|c|c|c|c|c|c|c|}
\hline & $\begin{array}{c}\text { Compliance } \\
\text { Basis }\end{array}$ & Order Basis & $\begin{array}{c}\text { Diffusion } \\
\text { Mechanism }\end{array}$ & Logic Type & $\begin{array}{l}\text { Process } \\
\text { Indicator }\end{array}$ & $\begin{array}{l}\text { Emotional } \\
\text { Response }\end{array}$ & $\begin{array}{c}\text { Legitimacy } \\
\text { Basis }\end{array}$ \\
\hline $\begin{array}{l}\text { Regulative } \\
\text { Elements }\end{array}$ & $\begin{array}{l}\text { Equity } \\
\text { Response }\end{array}$ & $\begin{array}{l}\text { Regulative } \\
\text { Rules }\end{array}$ & Compulsive & Instrumental & $\begin{array}{l}\text { Rules, Laws, } \\
1 \text { Rewards and } \\
\text { Punishments }\end{array}$ & $\begin{array}{l}\text { Guilty/Not } \\
\text { Guilty }\end{array}$ & $\begin{array}{l}\text { Legal } \\
\text { Sanction }\end{array}$ \\
\hline $\begin{array}{l}\text { Normative } \\
\text { Elements }\end{array}$ & $\begin{array}{l}\text { Social } \\
\text { Responsibility }\end{array}$ & $\begin{array}{l}\text { Binding } \\
\text { Expectations }\end{array}$ & Normative & Appropriate & $\begin{array}{l}\text { Qualification } \\
\text { Certificate and } \\
\text { Qualification } \\
\text { Recognition }\end{array}$ & $\begin{array}{l}\text { Shameful/ } \\
\text { Honorable }\end{array}$ & $\begin{array}{l}\text { Moral } \\
\text { Domination }\end{array}$ \\
\hline $\begin{array}{l}\text { Cultural- } \\
\text { cognitive } \\
\text { Elements }\end{array}$ & $\begin{array}{l}\text { Consistence of } \\
\text { Views }\end{array}$ & $\begin{array}{l}\text { f Constructive } \\
\text { Schema }\end{array}$ & Imitation & Imitation & $\begin{array}{l}\text { Common Belief } \\
\text { and Common } \\
\text { Action Logic }\end{array}$ & $\begin{array}{l}\text { Confirmed/ } \\
\text { Hesitated }\end{array}$ & $\begin{array}{l}\text { Recognized } \\
\text { Cultural } \\
\text { Support }\end{array}$ \\
\hline
\end{tabular}

This analysis method has a strong reference value for the study of the institutional complementarity of modern apprenticeship. Firstly, it takes the institutional elements, not the institution itself as the unit for analysis, which is in line with the institutional complexity. Modern apprenticeship system is not an independent institution with clear-cut boundaries, but a collection of institutional elements with obvious cross-border characteristics and covers various aspects. As for such a combination of institutions, a better method to analyze it is to flexibly discuss the institutional elements it contains rather than rigidly dissect it into several institutions. Secondly, the modern apprenticeship system contains all these three kinds of elements. Therefore, the division of institutional elements can help better understand the way these institutions function and the way they relate to each other.

When the structural elements of the institutional elements are determined, the next step is to make clear how to evaluate policy elements. The institution is considered to be functional; it is because it has functions that can satisfy human needs that the institution is artificially selected and created. As a result, the evaluation of institutional elements mainly concerns with its degree of realization of its expected function. In terms of modern apprenticeship system, the functional objectives of the relevant institutional combinations can be summarized into the following two aspects: (1) promoting and maintain the quantity of the modern apprenticeship system; 
and (2) promoting and guaranteeing the quality of the modern apprenticeship system. Besides, these three elements should be analyzed into three levels: strong, medium and weak. Based on the above analysis, this paper constructs a theoretical framework of institutional complementarity.

\section{The Analysis of the Modern Apprenticeship System in China and in Germany}

\section{Germany's Modern Apprenticeship System}

The sound development of Germany's industrial system is inseparable from a sound system of skilled personnel training. However, the apprenticeship-based skills formation system is the cornerstone that supports the social cooperation between employers and employers (Streeck, 2003; Estevez-Abe, Iversen\& Soskice, 2001). The modern apprenticeship system, also called dual system, is a major form of German vocational education. There are more than 5.5 million new apprentices every year, and the total number of apprentices that take the dual system accounts for about $60 \%$ of the people who accept vocational education. This paper analyzes German modern apprenticeship system from the perspective of three fundamental elements.

\section{Regulative Elements}

The division system in the German education system provides a powerful regulative guarantee for the apprenticeship system to obtain sufficient high-quality source of students. For the students, German compulsory education begins at the age of six and after four years, students enter the orientation class. Another two years later, apprentices are diverted into the mainstream middle school, practical middle school or grammar school. Most of the students in the practical middle school and grammar school will enter schools with a dual system or full-time vocational schools. This kind of division provides sufficient students for carrying out the apprenticeship system, and high quality graduated students in turn enhance enterprises' willingness to carry out the apprenticeship system. This process protects the reputation and status of the dual system as well as enhances its appeal to students.

\section{Normative Elements}

German youth's favor for apprenticeship is primarily attributed to the German enterprises' identity recognition of and employment preferences for students who have accomplished an apprenticeship system. Compared with students in full-time vocational school, apprentices can obtain more and better employment opportunities. This is because the apprenticeship system is well recognized by German enterprises. Besides, industry associations also organize special qualification examinations to identify apprentices' learning outcomes or even exclude full-time vocational school graduates from such examinations. Consequently, the apprenticeship system provides reliable identity recognition and career expectation for German young people. Apart from this, Germany has a rich and comprehensive system for professional enlightenment and career guidance, which offers employment-related education, experience and counseling to students at an early stage so it enhances students' recognition of the apprenticeship system. Every primary and secondary school in Germany has a full-time career instructor to provide guidance to students on affairs like career choices, the dual system and applying for qualification accreditation. Seventh-graders can take a career potential analysis while 
eighth-grade students have a two-week professional experience. This institutional arrangement contributes to German teenagers' high recognition of the apprenticeship system.

\section{Cultural-cognitive Elements}

German cultural particularity and strong apprenticeship tradition also provide guarantee for the implement of apprenticeship system. In the traditional religious culture of Germany, occupation is a "bounden duty" assigned by God and everyone has the responsibility to do their best. People with skills are highly respected. Therefore, it is seen as a matter of course to obtain the qualifications for technical occupation through the apprenticeship system. The apprenticeship system enjoys a higher status than other full-time vocational education in both the education system and the labor market.

\section{The Order-class Mode in Chinese Higher Colleges}

The "digging" behavior between enterprises can lead to an inability to establish an internal skill formation mechanism (Woeste \& Demchick, 1996). The early collective bargaining system in Germany effectively prevented this kind of dig-out, and the stable employment relationship laid the institutional foundation for the modernization of the apprenticeship (Becker \& Pau, 1977; Hall \& Soskice, 2001). In China, due to the high mobility of the workforce in the labor market and the imperfection of relevant policy institutions, the apprenticeship in a strict sense has not been popularized in institutions of higher learning. Nevertheless, there is already an order system training mode resulting from the school-enterprise cooperation in some vocational colleges with good student resources. Zhejiang Financial College is a good example. As the first demonstration vocational college in China, it has cultivated more than 5,000 bank presidents. Such powerful alumni resource provides guarantee for the employment of its students as the college has signed order-training agreements with banks like Industrial and Commercial Bank of China (ICBC), Postal Savings Bank of China (PSBC), China Zheshang Bank (CZB) and so on. After graduation, students are directly assigned to work at different bank outlets. Based on the framework of institutional complementarity analysis, this paper takes Zhejiang Financial College as an example to illustrate the school-enterprise cooperation method of the order-class.

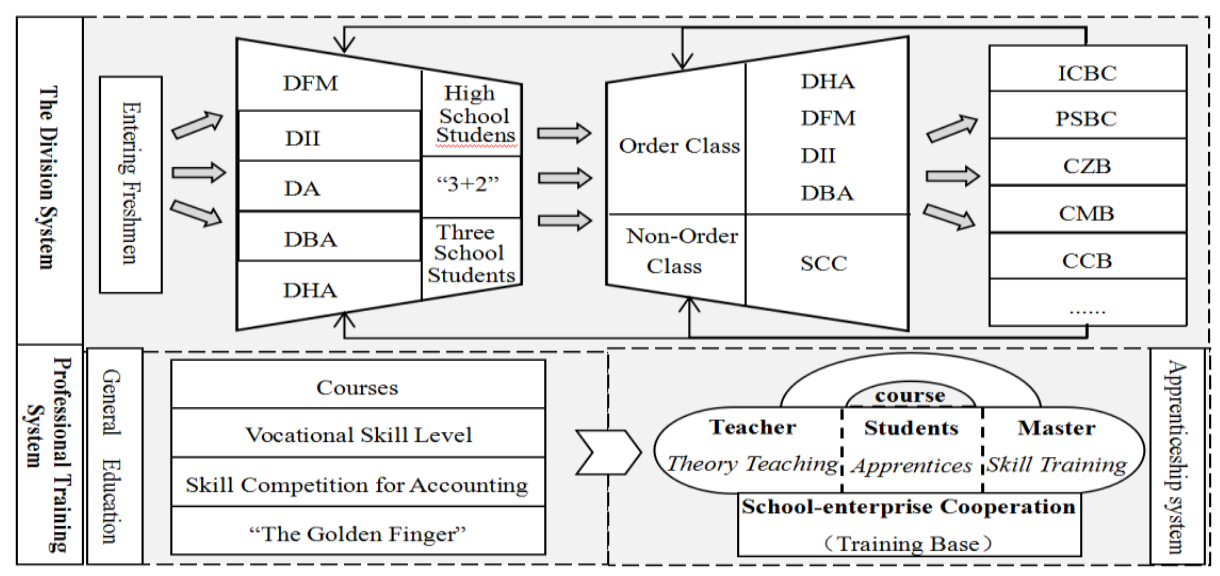

Figure 1. The Order-class Student Training Method of Zhejiang Financial College 


\section{Regulative Elements}

First of all, the establishment of a dividing system provides strong regulative guarantee for the order-class. China adopts nine-year compulsory education. When students have graduated from junior high school, they can either apply for a high school or choose to go to secondary schools including vocational school and special school. As Figure 1 shows, Zhejiang Financial College takes a first division of students when the freshmen enter the college. This division is based on the dimensions of major and characteristics of the students. According to their major, students will be divided into secondary colleges like Department of Investment and Insurance (DII), Department of Humanities and Arts (DHA), Department of Financial Management (DFM) and Department of Accounting (DA). According to the different enrolling forms of the students, they will be divided into "ordinary high school students", "three schools students" and " $3+2$ students", and then enter different classes that are separately established. In the second year after the enrollment of freshmen, students are divided for the second time. In accordance with the cooperative agreements with the major banks, students are organized to take intraschool interview for attending the order-class and only those who have passed the interview can enter the orderclass, as is shown in Figure 1. The student status and course arrangement of those students in the order-class are transferred to "Silver Collar College" (SCC), a virtual secondary college that are separately established to cultivate students in the order-class. Statistics from previous years shows that around $43 \%$ of all students have entered the order-class of different banks. On the other hand, the job vacancies in banks also have an impact on the first and second division of the students in college.

Secondly, the professional training and skill appraisal offer an optimal regulative path for the order-class. In addition to the regular courses, Zhejiang Financial College also adds a practical banking skill course which teaches students about counting cash, organizing bank vouchers and Wubi input skills. Each semester, a "financial basic professional skills assessment" will be arranged and to be qualified is a precondition of entering the order-class. As shown in Figure 1, after entering the order-class, the students' training mode is officially transferred to system which is similar to a batch "modern apprenticeship system". In terms of the course setting, "Silver Collar College" reorganizes the courses according to the specific employments requirements of the bank. As for faculty, apart from original professional teachers, there is also experienced banking staff to teach banking skills. In the second half year of the grade three, students are arranged to do internships in the outlets of the banks that have cooperation with the college and specialized personnel in the banks will further strengthen student's skills. In terms of the practical work experience, the college has set a "customer service center" in cooperation with China Zheshang Bank in the "Jintong Teaching Building", where the regular workers if the China Zheshang Bank normally works. The students of the order-class can apply for a visit and experience the working atmosphere by themselves. Such kind of training and assessment mechanism guarantees the quality of the students in the order-class form the system-setting level.

\section{Normative Elements}

Firstly, because the banks have a preference for students in the order-class, the students of Zhejiang Financial College favor the order-class. Before the selection of the students to be in the order-class, the college organizes various forms of skill assessments to assess the students' ability. After students have entered the order-class, the school offers more targeted training and testing for them. The high-quality talents provided by 
the college promote the banks' recognition of the order-class mode. As a result, banks allocate more basic positions to students in the order-class. In recent years, as the China's economic growth has slowed down, the employment market is highly competitive. Compared with other students form vocational schools, the mode of order-class can assign work for students, which gives students good employment expectations.

Secondly, students highly recognize the employment situation after entering the order-class. The college has perfect career enlightenment. After the enrolment of freshmen, the college promotes the order-class early and regularly organizes the alumni who work in the banks to return so as to give relevant advice for students. Besides, the college provides a career counseling course for students in the first year, in which the career promotion channel of working in banks will be introduced to enhance the students' recognition and sense of purpose. The tracking and investigation of the students in the Department of Accounting Zhejiang Financial College in 2014-2017 showed that about $82.4 \%$ of first-graders take the bank order-class as the first employment intention.

\section{Cultural-cognitive Elements}

In the traditional Chinese concept of employment, civil servants are viewed as "silver bowls" while staff in banks and other state-owned enterprises are regarded as "iron bowls", which is synonymous with stable employment and good treatment. In China, many students with a master's degree also apply for bank tellers. Therefore, it will provide a sense of achievement for students with college degree to work in a bank. During the interview of order-class, the student's hometown and the employment place are generally required to be unified. Working in the hometown also offers a sense of honor to students. Even if the students may change jobs in the future, the work experience in the bank gives them a greater competitive advantage in the labor market. All of these enhance students' enthusiasm for entering the order-class.

\section{A Comparative Study of Institutional Complementarity of German Modern Apprenticeship System and Chinese Order-class Mode}

The famous comparative educator Sadler once pointed out that, the specific methods or elements of the education system are often deeply rooted in the soil of the system itself, closely linked to the conditions on which they depend. It will only result in failure to simply transplant the foreign policies into one's own country. This rule can also apply to the modern apprenticeship system. This paper takes the perspective of system theory to interpret the institutional system and institutional complementarity, looks for the essential different and common rules from institutional complementarity so as to provide experiences that other countries can learn from.

\section{Differences in Institutional Complementarity}

In this paper, the regulative, normative and cultural-cognitive elements are adjusted into three basic elements with directional three-dimensional relationships. In the directionality of each dimension, there is a division of degree into strong, medium and weak. A comparison of institutional complementarity of the German 
apprenticeship system and the Chinese order-class mode is carried out on the basis of this framework, as shown in Figure 2.

\section{Regulative Elements}

The division system of German education starts early. When students are 12 years old, they are diverted to the mainstream middle school, practical middle school or grammar school. Its implementation scope is the whole country and the policy is compulsive. Therefore, its overall intensity is strong. The division system of order-class in Zhejiang Financial College begins after the enrolment of first-graders, and is a small-scale division within the college with a weak overall intensity.

\section{Normative Elements}

Both the German apprenticeship system and the Chinese order-class mode are recognized by students in terms of personal emotion and professional development. However, nowadays, more vocational colleges in China have been upgraded to undergraduate colleges. The competitiveness of higher vocational school students is decreasing and the quantity and quality of jobs provided by enterprises are on the decline. Under this circumstance, the order-class has become less popular among the students. Nevertheless, the German business circle firmly believes that, vocational training is the independent responsibility of the economic community. Even in today's fierce labor market, German enterprises still stick to such responsibility and the support from the business field contributes to the continuation of apprenticeship system after students' graduation. At the same time, apprentices also regard participating in relevant training as their own social obligations (Zacher, 1982). As a result, the overall intensity of German system is strong while that of Chinese mode is weak.

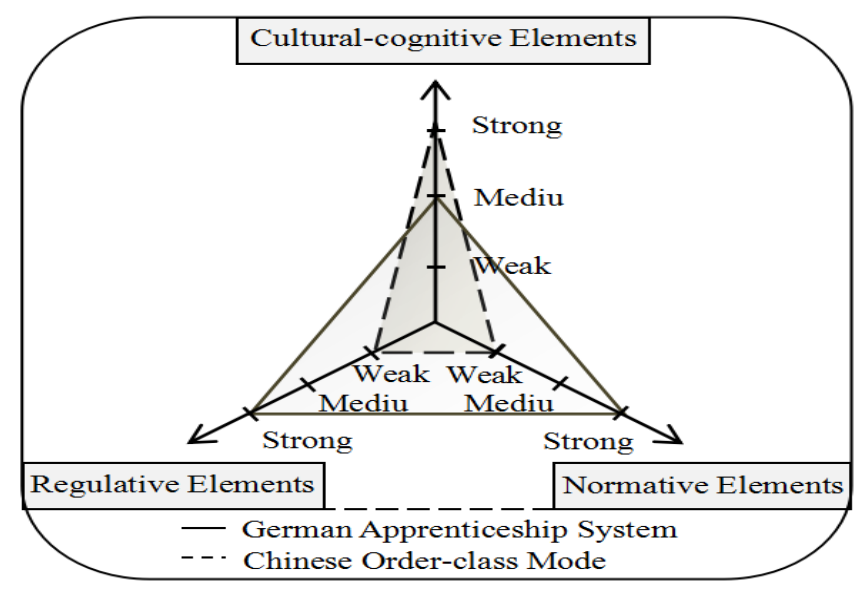

Figure 2. The Comparison of the Institutional Complementarity of German Apprenticeship System and Chinese Order-class Mode

\section{Cultural-cognitive Elements}

Tradition German religious culture and a strong professional training system provide guarantee for the apprenticeship system, but as the labor market is experiencing globalization, this influence has been weakened 
so the overall intensity is medium. At the same time, in China, the traditional employment culture favor the banking work so students in the bank order-class have unique competitive advantages in the cognition level so its overall intensity is strong.

To summarize, the same core of the institutional complementarity of the two countries is to provide apprentices with good career prospects, but the degree and methods of the two systems are different. The complementarity of German apprenticeship system is manifested by the mutual enhancement of the three basic elements so it's more balanced, while the Chinese order-class system is characterized by the compensation of cultural-cognitive elements for normative and regulative elements.

\section{Rules of Institutional Complementarity}

The Two Major Forms of Institutional Complementarity as Mutual Enhancement and Mutual Compensation

A balanced system tends to reinforce each other while a developmental system tends to compensate each other. The German apprenticeship system is a balance system with relatively perfect elements in each dimension and there is a mutual enhanced and lock-in relationship between these elements. The order-class mode of Zhejiang Financial College belongs to a developmental system. It is base on the basic orientation of higher vocational colleges and the good reputation in the banking system. The degrees of perfection of the three kinds of elements are quite different. Therefore, this mode needs to be continuously improved to compensate its original deficiencies so as to promote its sound development.

The Core of Institutional Complementarity as Providing Good Career Prospects

In Germany, the career prospects of apprentices are very promising benefiting from the high recognition from the business circle and the general respect for technical workers from the society. As for the Zhejiang Financial College, the employment distribution system implemented in the order-class also provides students with good employment expectations.

A Virtuous Circle of Institutional Complementarity is Inseparable from Quality Assurance

The fundamental criterion for testing the strengths and weaknesses of a education system is the quality of graduates. In Germany, the quality assurance system is relatively perfect as the apprenticeship qualification system, standards, evaluation and other guarantee systems have penetrated into the whole process of talent cultivation. Regulative, normative and cultural-cognitive elements are superimposed on each other so as to ensure the quality assurance system. In Zhejiang Financial College, the skill training and assessment of students are integrated in all aspects of the order-class. First-graders need to practice basic skills like counting cash and five-stroke typing. Each semester, they should take a skill assessment, which is a precondition to enter the orderclass. After they have entered the order-class, they have customized courses. The training mode in which the school teacher and the practical elite tutor cooperate together and real-time evaluation is carried out ensures the quality of the order-class.

The Interrelationship between Quantity and Quality in Institutional Complementarity 
Scale development and quality development are a dialectical unity. The virtuous circle of German modern apprenticeship system is inseparable from a large scale. Each year, there are about 500,000 more apprenticeship contracts added, and the proportion of enterprises that adopt the apprenticeship system is about $30 \%$. The change in quantity leads to the change in quality. In terms of the order-class in Zhejiang Financial College, the complementraity of regulative, normative and cultural-cognitive, as well as the large number of graduates transferred to the national banking system contribute to its success. The great number of students who join the order-class provides not only sufficient samples for the college to revise its training process but also enough audiences for the college to develop specialized training courses. In addition, the vast number of graduates in the banking system becomes alumni resources and adds emotional bonds to the school-enterprise cooperation.

\section{Policy Recommendation}

Any goal that the market economy cannot achieve independently should be assisted by national policy intervention (Zacher, 1982). Modern apprenticeship has proved to be an effective way to train technical talents. Due to the imperfect labor market in most developing countries, government policies are needed to guide enterprises and schools to build apprenticeships. The perspective of institutional complementarity allows us to re-examine the institutional diversity of various forms of the modern apprenticeship system and provides a basis for rational design of relevant institutions. In terms of the way to set modern apprenticeship system in China, this paper proposes the following recommendations from the government level:

Firstly, students should be motivated to participate in the modern apprenticeship system. The government should encourage high-quality enterprises to sign an order-class training agreement with colleges to attract students to participate in the apprenticeship system. Secondly, the modern apprenticeship system should be piloted in key colleges to accumulate practical experience. It should be noted that the apprenticeship pilot program should not only focus on the quantity, but also constantly revise the system design to ensure the training quality. Finally, the concept of the modern apprenticeship system should be localized. When this system was first implemented in countries like Germany and Britain, it was adjusted according to their national conditions. Therefore, the pilot reform in developing countries should not mechanically copy the foreign system but seriously explore the existing domestic institutional environment and institutional elements as well as rationally design relevant institutions taking the perspective of complementarity in order to fully exert the expected effects of the institution.

\section{References}

Becker, P. W., \& Pau, L. F. (1977). Recognition of patterns using the frequencies of occurrence of binary words. IEEE Transactions on Systems, Man, and Cybernetics, 1(7), 72.

Hall, P. A. (2001). Varieties of capitalism: The institutional foundations of comparative advantage. D. W. Soskice (Ed.). Oxford: Oxford University Press. 
Thelen K. (2005). How Institutions Evolve: The political economy of skills in Germany, Britain, the United States, and Japan. Enterprise \& Society, 7(1), 40-3. http://dx.doi.org/10.1017/CBO9780511790997

Estevez-Abe, M., Iversen, T., \& Soskice, D. (2001). Social protection and the formation of skills: a reinterpretation of the welfare state. Varieties of Capitalism: The institutional foundations of comparative advantage, 145, 145-183. http://dx.doi.org/10.1093/0199247757.003.0004

Hall, P. A., \& Soskice, D. (2003). Varieties of capitalism and institutional complementarities. In Institutional Conflicts and Complementarities (pp. 43-76). Springer, Boston, MA.

Woeste, S., \& Demchick, P. (1996). A slow bacterial growth curve exercise for laboratory classrooms. Journal of Biological Education, 30(2), 91-92. http://dx.doi.org/10.1080/00219266.1996.9655484

Streeck, W. (2003). From stability of stagnation: Germany at the beginning of the twenty-first century. West European Politics, 26(4), 1-34. http://dx.doi.org/10.1080/01402380312331280668

Witte, K. D., Nicaise, I. \& Lavrijsen, J. (2013). The impact of institutional context, education and labour market policies on early school leaving: a comparative analysis of EU countries. European Journal of Education, 48(3), 331-345.

Zacher, H. F. (1982). Social market economy, social policy, and the law. Zeitschrift Für Die Gesamte Staatswissenschaft, 138(3), 367-388. http://dx.doi.org/10.2307/40750541 